\title{
Discussion of ultrashort voltage pulses electrochemical micromachining: a review
}

\author{
Sebastian Skoczypiec ${ }^{1}$
}

Received: 12 November 2015 / Accepted: 14 January 2016 / Published online: 18 February 2016

(C) The Author(s) 2016. This article is published with open access at Springerlink.com

\begin{abstract}
One of the most effective way of electrochemical machining (ECM) accuracy increase is to carry out process with application of voltage pulses. In one of the variants of ECM, ultra short (nono- or picosecond range) voltage pulses are applied. It gives possibility to achieve high localization of electrochemical dissolution process and allows to machine microparts with accuracy less than $0.01 \mathrm{~mm}$. However, because of the process principles, this variant of ECM has number of limitations which stop its wider application in micromanufacturing industry. Based on the literature review, the physical principles of ultrashort voltage pulses electrochemical machining were presented and anodic dissolution localization issues were discussed. Also, differences between other electrochemical machining variants were underlined. It gave possibility to identify limitations and future perspectives of industrial applications.
\end{abstract}

Keywords Micromachining - Electrochemical machining · Ultrashort pulses

\section{Introduction}

In aspect of machining parts miniaturization, manufacturing methods in which material is removed by electrical, thermal, or chemical interaction have a number of advantages in comparison to cutting. The most important of them are: no mechanical contact between tool and workpiece (smaller

Sebastian Skoczypiec

skoczypiec@mech.pk.edu.pl

1 Institute of Production Engineering, Cracow University of Technology, Al. Jana Pawla II 37, 31-864 Krakow, Poland deformations and vibrations in machining area, less chance to damage tool and workpiece), machinability does not depend on mechanical properties of material (it depends on thermal, electrical, optical, or chemical properties of material), possibility of machining broad range of materials, and efficiency in the production of prototypes and small series (flexibility).

Application of unconventional manufacturing methods for microparts shaping is connected with top-down philosophy, what means production of smaller parts with application of appropriately modified production systems which are commonly used in macromanufacturing. These modification relate to increase of machining resolution and improvement of machine-tools and tooling accuracy [30].

Machining resolution is strictly connected to unit removal (UR), which is defined as part of the workpiece removed during one cycle of removal action [44]. For example in electrodischarge machining, it is volume of material eroded in single discharge and in cutting it can be identified with minimum chip thickness. UR determines the smallest adjustable dimension and precision of machining, therefore in micromachining UR should be as small as possible.

Electrochemical machining (ECM) is an important technology, especially in machining difficult-to-cut alloys and to shape free-form surfaces. In ECM, material is removed by electrochemical dissolution process and theoretically the smallest UR is single ion; however, achieving high localization of dissolution process is a key problem. The anodic dissolution is accompanied by disadvantageous effect of spreading the material removal zone on the distance significantly higher than interelectrode gap thickness. It results from distribution of electric field in machining area and is called as delocalization effect. Therefore, the electrochemical dissolution should be controlled and limited only to specific areas. Several studies aimed at improving the 
conditions of electrochemical dissolution were conducted, and the most effective seems the application of a ultrashort pulse voltage (in nano- or picosecond range). However, despite of large potential of this process in laboratory scale, this variant of electrochemical machining has not yet found wide application in the industry.

In the paper, physical principles of ultrashort voltage pulses electrochemical machining were presented and anodic dissolution localization issues were discussed. It gave possibility to identify limitations and perspectives of industrial applications of this micromachining method.

\section{Characteristic of electrochemical micromachining}

In electrochemical machining, allowance is removed by electrochemical dissolution by applying voltage (constant or pulse) between two electrodes: tool (cathode) and workpiece (anode). In outer electric circuit, charge is transported by electrons but in space between the electrodes there is an electrolyte and electric charge is transported by ions. The change of electronic to ionic conduction is possible due to electrochemical reactions that take place on the electrode-electrolyte borders. One of these reactions is dissolution of anode (workpiece) material. One can state the following advantages of this process $[3,8,15]$ : no electrodetool wear, high productivity (significantly higher than in electrodischarge micromachining), and good surface quality (machining allowance is removed atom by atom via the electrochemical dissolution process in a temperature lower than $373 \mathrm{~K}$, which introduces no significant changes in the surface layer of the machined material). Additionally, machining productivity does not depend on the material mechanical properties. Allowance in electrochemical micromachining (ECMM) can be removed in electrochemical sinking or drilling [1, 47] and in the kinematics of milling with the application of a universal electrode-tool (3D-ECMM) [15, 17, 26, 42]. In the former, the shape of the machined surface is a reproduction of the electrodetool shape, and in the latter, it is a reproduction of the electrode-tool path in 3D space. In the electrochemical sinking process, the most important problem is to manufacture a small electrode-tool with a complicated shape. Therefore, the electrode manufacturing cost is high and the range of dimensions is very limited. Another problem is efficient supply of an electrolyte to the gap. In 3D-ECMM, shape of the parts results from three-dimensional electrode movement, therefore, a simple electrode-tool shape can be applied (i.e., cylindrical with a flat or spherical tip), which significantly decreases the cost of manufacturing. However, a special 3-D drive system application is then necessary.
The main problem in ECMM is to create conditions for the electrochemical dissolution localization. During the process, the tool and the workpiece are in distance equal to interelectrode gap thickness $S$ but area of anodic dissolution is spreading over much greater distances than $S$. It cause that area of dissolution is larger than the area of the electrode tool, what is the reason for machining inaccuracy, an increase in surface roughness and pitting occurrence.

Electrochemical machining accuracy is connected to current density distribution over the machined surface. Therefore, modification of the primary current density distribution (which results from the electrode and workpiece geometry) is the main area of research in this field. One can state the following solutions for the increase in electrochemical machining accuracy [8]:

- Decrease of the interelectrode gap.

- Proper selection of the electrolyte.

- Application of the gas-liquid mixture as an electrolyte.

- Special design and/or insulation of the electrode tool.

- Application of a pulse voltage.

From the items listed above, the most effective is the application of a pulse voltage [3, 7, 8]. Taking into account the pulse time $t_{i}$ duration pulse electrochemical machining (PECM) can be divided into three cases:

- With pulse time $t_{i}>1 \mathrm{~ms}$,

- With pulse time in the range of $t_{i}<1 \mathrm{~ms}$, (usually $t_{i}$ in range $1-100 \mu \mathrm{s}$ ),

- With pulse time $t_{i}<500 \mathrm{~ns}$.

The pulse time range for these cases results from the conditions of the electrochemical dissolutions and physical phenomena responsible for dissolution localization.

From an electrochemical point of view in the first two cases, the process is carried in a diffusion limited state, which generally means that distribution of current density $i$ is in close relation to the physical properties of the electrolyte ( $i$ is mainly dependent on concentration overpotential). In the first case, the main reason for applying voltage pulses is to avoid the critical conditions (i.e., electrical discharges); it makes possible machining with a smaller interelectrode gap. Additionally, the increase of the machining accuracy results from a reduction of the change of electrolyte properties along the interelectrode gap (reducing the impact of electrolyte conductivity changes on shape errors) $[21,35,36]$. A decrease of the pulse time to the microsecond range enhances these effects, which causes further accuracy improvement. This results from the relations between voltage drop, electrolyte temperature, and gap thickness, which define the current density $i$. Due to the smaller gap thickness, the electrolyte temperature increase $\Delta T$ is more intensive, which is the reason for a more intense electrolyte conductivity increase. Therefore, machining with higher 
current density $i$ is possible. It gives opportunity to use relations $\eta k_{v}(i)$ and $i(S)$ to localize anodic dissolution in areas where the gap is smaller ( $\eta k_{v}$ - electrochemical machinability, $S$ - interelectrode gap thickness). It is worth underlining that the above relations are valid for a limited range of $t_{i}$. The criteria of $t_{i}$ selection is an increase of $\frac{d v(S)}{d s}(v$-slope of dissolution) along with avoiding electrolyte boiling in the gap. Microsecond PECM can be adopted for precision and micropart manufacturing [2, 27, 31, 45, 48], and the limits of adaptation are defined by critical states in the gap [22]. With optimal dissolution conditions, the accuracy of this PECM variant reaches $10 \mu \mathrm{m}$.

In electrochemical machining with nanosecond voltage pulses (ns-PECM), current density $i$ is determined by activation overpotential, and the dissolution process is driven by the periodic electric double layer charging and discharging process. The time of double layer charging to the activation overpotential depends on gap thickness, therefore, the voltage pulse length can define the spatial resolution of machining (pulse time determine how far from the tool workpiece surface reach activation overpotential). According to the Butler-Volmer equation (valid only in an active state of dissolution), the current density $i$ is exponentially related to the overpotential, therefore, a small change of the electrode potential leads to a large change of the current density, thus the additional effect of dissolution localization occurs [6, 18, 19, 40]. Such an effect is irrelevant in machining with a longer pulse time $\left(t_{i}>0,5 \mu \mathrm{s}\right)$ because the double layer is charged uniformly over the machining surface, and machining is carried out in the diffusionlimited state (the current density is determined by transport phenomena in the gap). The ns-PECM process has been developed especially for micropart manufacturing and gives the possibility of shaping parts with dimensions of tens of micrometers with a resolution $<1 \mu \mathrm{m}$.

\section{The specificity of ultrashort pulse electrochemical machining (ns-PECM)}

\subsection{The physical principle of (ns-PECM)}

The conception of ultrashort pulse electrochemical machining was developed by professor Rolf Schuster in MaxPlanck at the end of nineties of the last century. Originally, the research was carried on a scanning tunneling microscope platform [39], using — as a electrode tool-the tip of the microscope. The obtained results gave possibility to develop fundamentals of ultrashort pulse electrochemical machining technology [6, 16, 18-20, 23, 24, 40].

In general, electrochemical processes depends on potential difference in electrical double layer (EDL) and chemical composition of the inner Helmholtz plane. Electrical double layer can be approximated by flat-plate capacitor filled with ultrathin dielectric layer (thickness in range of solvent particles dimension) with charge defined by electrode equilibrium potential $E_{e q}$. The connection of the electrode to the external voltage source cause:

- rearrangement of the ions in EDL (it is proportional to the value of charge-transfer current density $i_{c}$ ),

- change of electrode potential $E$ (the measure of this change is overpotential defined as $\eta=E-E_{e q}$ ),

- mass transport via anode-electrolyte and cathodeelectrolyte interface (it is proportional to the Faraday (mass transport) current density $i_{f}$ ).

According to the analogy between EDL and flat-plate capacitor, the charge time constant $\tau$ can be defined by:

$\tau=R C=R \cdot c \cdot S$

where $R$-resistance of electrolyte, $C$-EDL capacity, $c$ specific EDL capacity, $S$-distance between electrodes (thickness of the interelectrode gap). In some approximation value of $\tau$ determines the duration of EDL charge or discharge for two electrodes separated by gap $S$. From relation (1), one can state that application of pulse time $t_{i}$ gives possibility to charge EDL up to specific capacity $c$ for values of $S$ for which time constant $\tau<t_{i}$. If we assume that value of $c$ corresponds with activation potential $\eta_{a}$ of the electrochemical dissolution reaction, from relation (1) results also, that workpiece will be actively polarized only in limited area of interelectrode gap. According to Butler-Volmer equation, the speed of electrochemical reaction is exponentially dependent from overpotential $\eta$ and small changes in potential cause large changes in the current density, and hence the dissolution rate (see Fig. 1) increases. It is worth to underline that such effect does not matter when machining with direct or pulse current with long pulse time. In such cases,

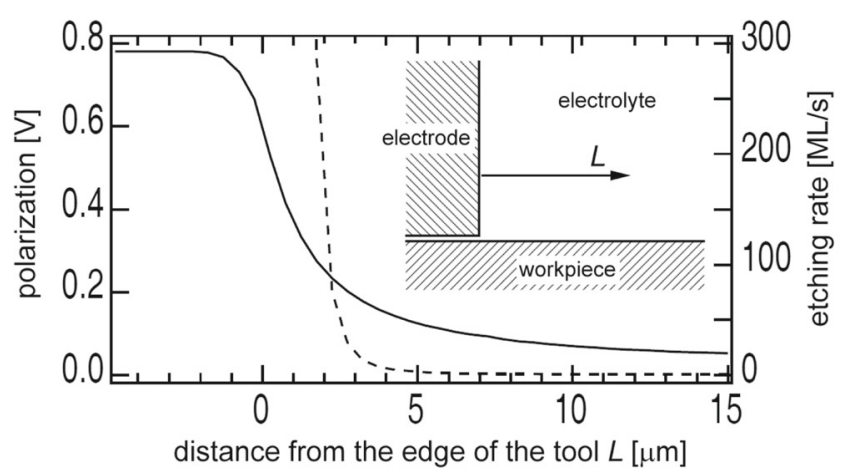

Fig. 1 Calculated polarization of the EDL on the workpiece at the end of a pulse $t_{i}=50 \mathrm{~ns},-1.6 \mathrm{~V}$ applied to a cylindrical tool electrode versus the distance from the edge of the tool (solid line) and corresponding $\mathrm{Cu}$ dissolution rate (dashed line); the zero of the $x$ axis is located at the edge of the tool $[16,40]$ 
EDL is uniformly charged over the machined surface and dissolution is limited by diffusion rate. From Eq. 1 results, that machining accuracy also depend on interelectrode gap thickness (bigger gap means bigger resistance $R$ ).

It is worth to underline that explanation of dissolution localization effect based on time constant $\tau$ is an approximation because it assumes only charge-transfer current $i_{c}$ and ignores the simultaneous flow of faraday current $i_{f}$ (the faraday current determine dissolution process). It was clarified and developed by Kozak et. al. [23-25] mathematical model which gives possibility to analyze relation between electrode potential, dissolution current, and electrical charge during ns-PECM process (Fig. 2).

The research carried out by prof. Schuster's group indicated possibility of high machining resolution increase. For example, for 1.4301 steel thickness of lateral gap $\approx 200 \mathrm{~nm}$ and edge radius $\approx 1 \mu \mathrm{m}$ was obtained [6]. Therefore, the amount of research works in this field have increased significantly. The research are mainly carried out in South Korea [1, 12-15, 34, 41], Singapore and China [10, 28, 46,
49-53], Poland [23, 24, 38, 43], and the USA [32]. These papers mainly concern issues of machining resolution and practical application of ns-PECM process. It is also worth to underline that important place among these studies take publications concerning mathematical modeling [23, 24].

\subsection{Electrode-tool and workpiece configuration in ns-PECM}

In classical ECM process, the electrode-tool and workpiece is connected to external power source and the voltage (constant or pulse) between tool and workpiece is stabilized at desired level. In such system, the potential of tool and workpiece surface results from the phenomena occurring in the gap between electrodes. While in ns-PECM, the potential of workpiece surface during pulse has to be maintained at constant level, therefore the machining is carried out with application of potentiostat and pulse generator (Fig. 3) what gives possibility to control the voltage difference between a workpiece and reference electrode. The current necessary (a)

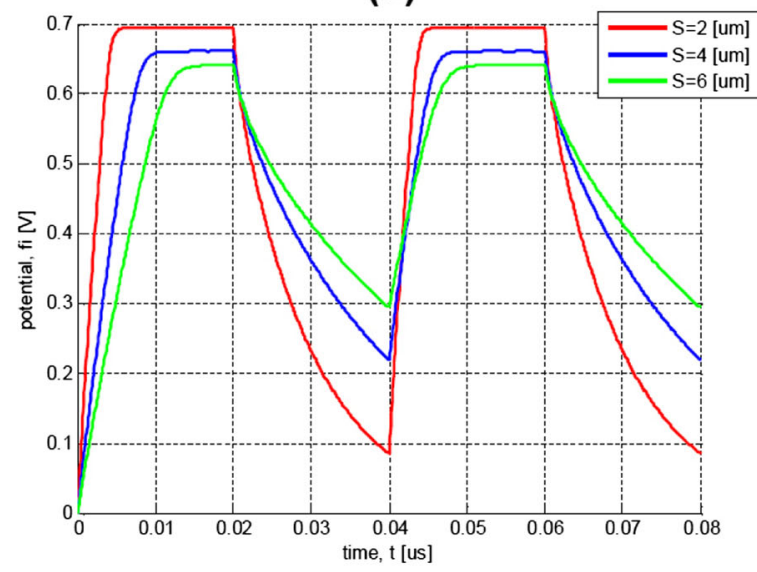

(c)

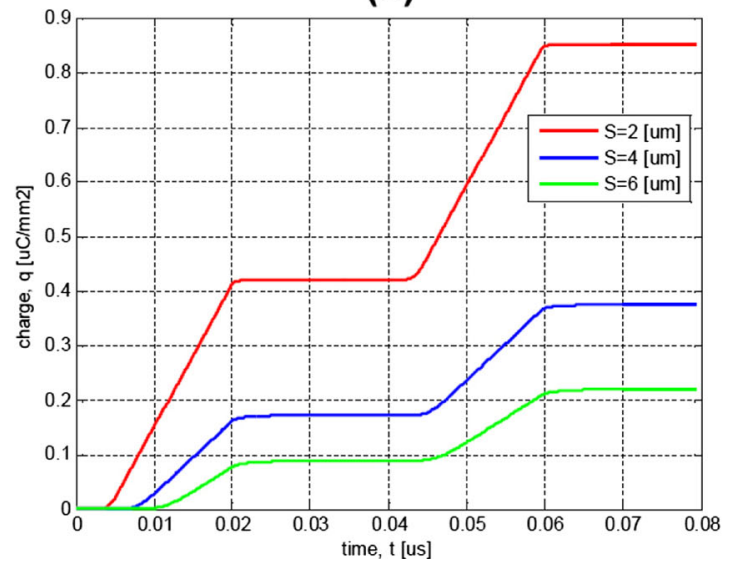

Fig. 2 Relation between electrode potential $\phi$ (a), dissolution current $i$ (b), and electrical charge $q$ (c) during ns-PECM process; results of computer simulation of two pulses sequence changes in time at gap (b)

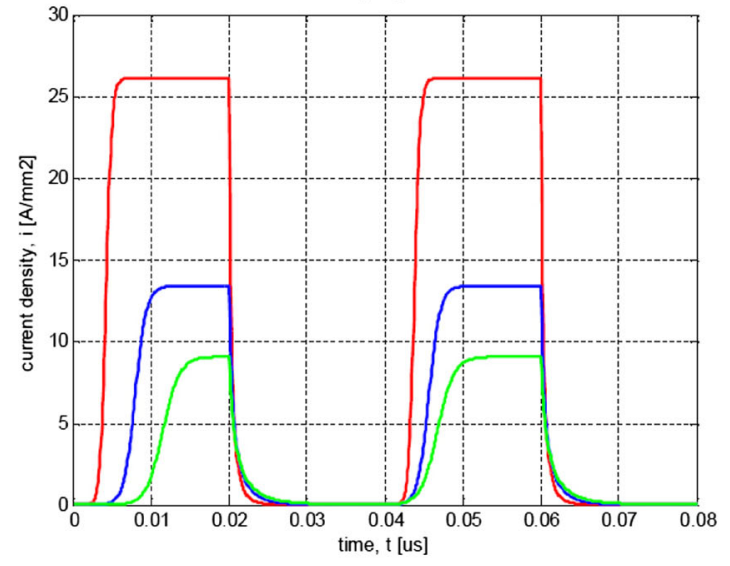

(d)

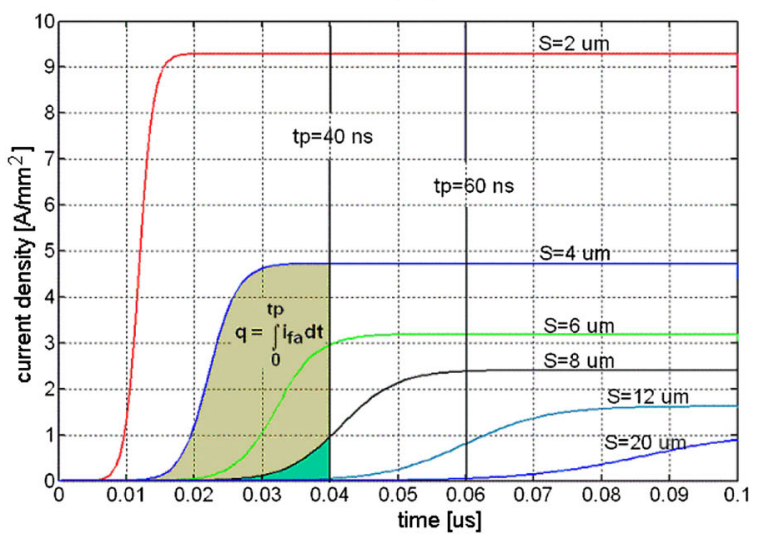

size $S=2 \mu \mathrm{m}, S=4 \mu \mathrm{m}$, and $S=6 \mu \mathrm{m}$; $\mathbf{d}$ change of anodic current density $i$ in time for different gap thickness [24, 25] 


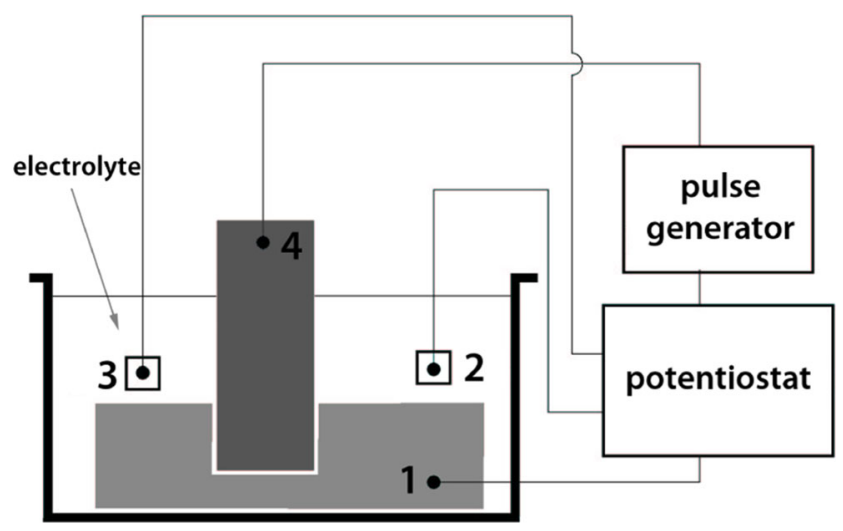

Fig. 3 Scheme of the electrode configuration in ns-PECM process; 1 workpiece (working electrode), 2 reference electrode, 3 auxiliary electrode, 4 electrode-tool [16]

to maintain a constant anode potential, flows through the auxiliary electrode.

The process of ns-PECM is carried in the interelectrode gap with thickness $S<10 \mu \mathrm{m}$ and the electrolyte forced flow is extremals difficult. This makes the dissolution in transpassive state impossible and the process is carried on in active state. As results from Pourbaix diagram, with the increase of electrolyte acidity passivation potential increases. Therefore, during the process, the acid electrolytes are used (i.e., for 1.4301 steel mixture of $3 \mathrm{M}$ $\mathrm{HCl}$ and $6 \mathrm{M} \mathrm{HF}$ ). Moreover, for $\mathrm{pH}<2$ oxide layers do not form and with change of electrode potential during dissolution a change of iron dissolved ions valence from $\mathrm{Fe}^{2+}$ to $\mathrm{Fe}^{3+}$ take place. For these reasons, application of acid electrolyte is one of the main condition for correct ns-PECM process $[6,16]$. To prevent corrosion is such a system anode and cathode have negative potential $(-200 \mathrm{mV})$ in relation to reference electrode.

\section{The localization of anode dissolution in ns-PECM}

\subsection{Localization factor}

One of the conditions of machining process adaptation for micromachining is decrease of unit removal (UR), which is defined as part of the workpiece removed during one cycle of removal action [44]. UR gives the limit of the smallest adjustable dimensions of the part, so UR of sub-micrometer range is required when the object size is very small or when high precision of the product is required.

In ECM, there is no direct contact between tool and workpiece (they are in distance equal to interelectrode gap thickness $S$ ), and area of anodic dissolution is spreading over much greater distances than $S$. These results from distribution of electrical field and current density in machining area and is called as delocalization effect. The suitability of ECM for micromachining can be described with localization factor $n$, which is defined based on $v_{n}(S)$ relation $\left(v_{n}\right.$
Fig. 4 Scheme of the ECM localization idea; a flat electrode, $\mathbf{b}$ shaped electrode, $\mathbf{c}$ relation of dissolution velocity $v_{n}(S)$ from interelectrode gap thickness $S, S_{L}$ limiting interelectrode gap thickness
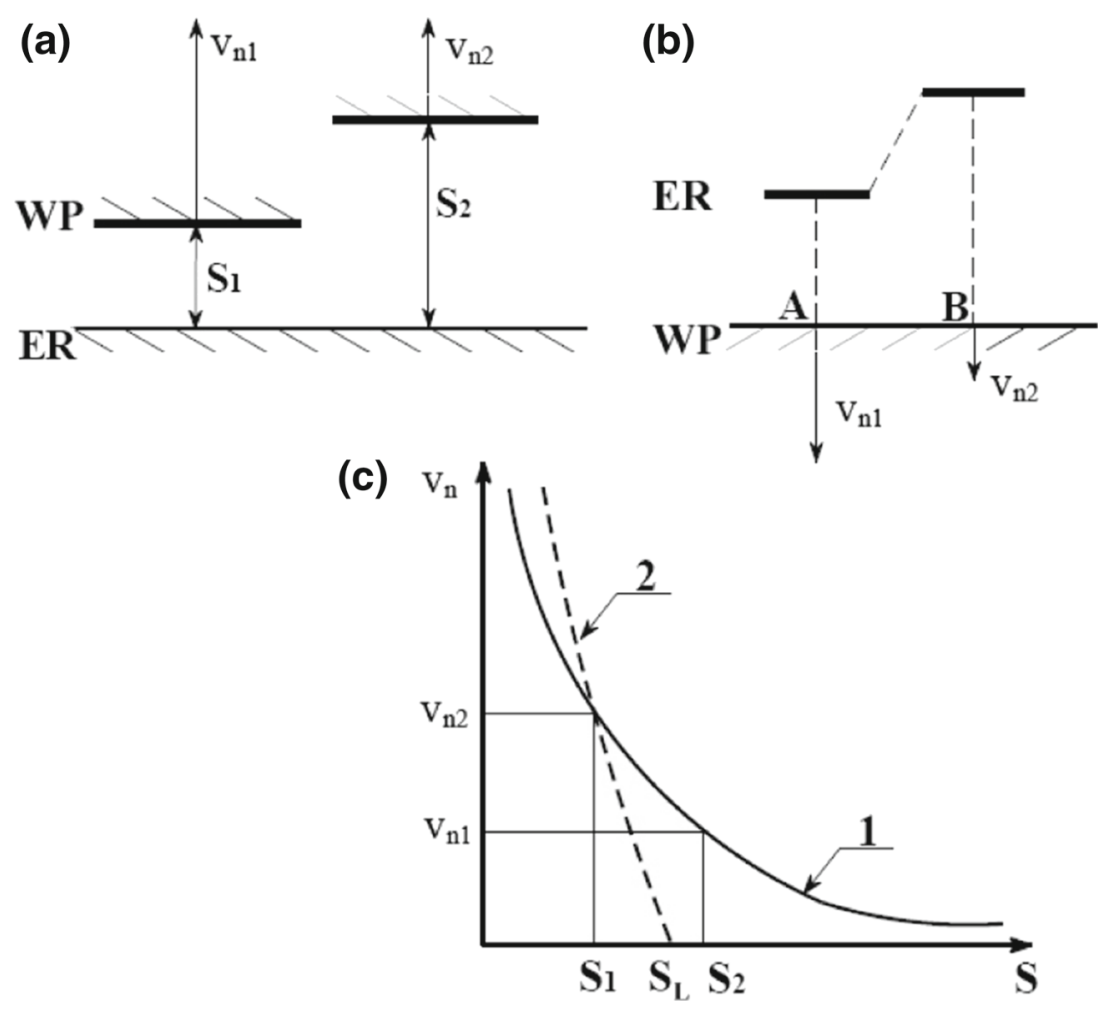
- dissolution velocity in direction normal to surface). For ideal ECM process $v_{n}=\frac{\text { conts }}{S^{n}}$ (curve 1 in Fig. 4 ) and, e.g., for $S_{2}=10 S_{1} v_{n 2}$ has relative big value $\left(10 \%\right.$ of $\left.v_{n 1}\right)$. In Fig. 4, curve 2 describes process with high dissolution localization, in which for $S>S_{L}$ dissolution process does not occur. So, the localization factor $n$ can be defined based on the relation between $\frac{v_{n 1}}{v_{n 2}}$ and $\frac{S_{2}}{S_{1}}$, which is as follows:

$\left(\frac{v_{n 1}}{v_{n 2}}\right)=\left(\frac{S_{2}}{S_{1}}\right)^{n}$

For ideal ECM process $n=1$ and to localize the dissolution $n$ should be as high as possible

\subsection{Factors determining the localization in ns-PECM}

First assessment of anodic dissolution localization for nsPECM was presented in [16]. In general, localization depends on voltage amplitude $U$ and pulse time $t_{i}$. The comparison of side gap for cavities machined with different values of $t_{i}$ and $U$ (Fig. 5) indicates exponential relation of accuracy from $U$. Relation from $t_{i}$ for ideal case (i.e., when dissolution current is determined by activation overpotential) has linear character (Fig. 6). The machining proces is carried out with retaliative small gap $(S<10 \mu \mathrm{m})$, therefore exchange of electrolyte with forced convection is extremely difficult. Only in initial period of dissolution impact of
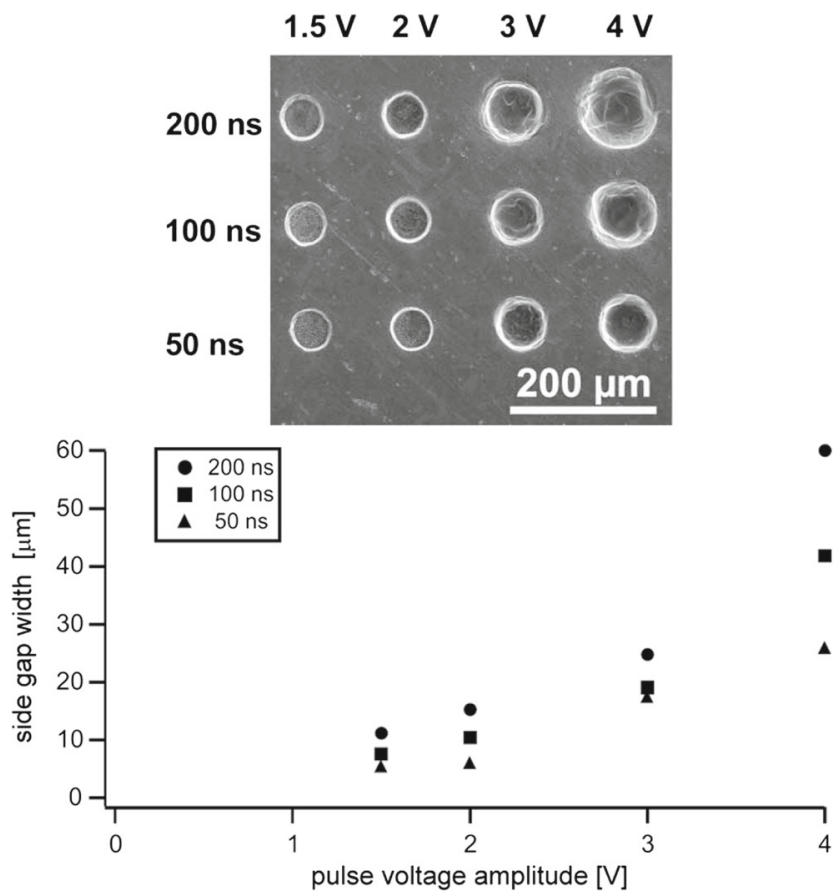

Fig. 5 Array of holes drilled with different pulse parameters into 1.4301 stainless steel. The diameter of the holes increases with both the pulse duration and the amplitude (tool: cylindrical Pt wire with $50 \mu \mathrm{m}$ diameter, electrolyte $3 \mathrm{M} \mathrm{HCl} / 6 \mathrm{M} \mathrm{HF}$, machining time: for voltage amplitude 1.5 and $2 \mathrm{~V}-5 \mathrm{~min}$, for 3 and $4 \mathrm{~V}-20 \mathrm{~s}$ ) [16]

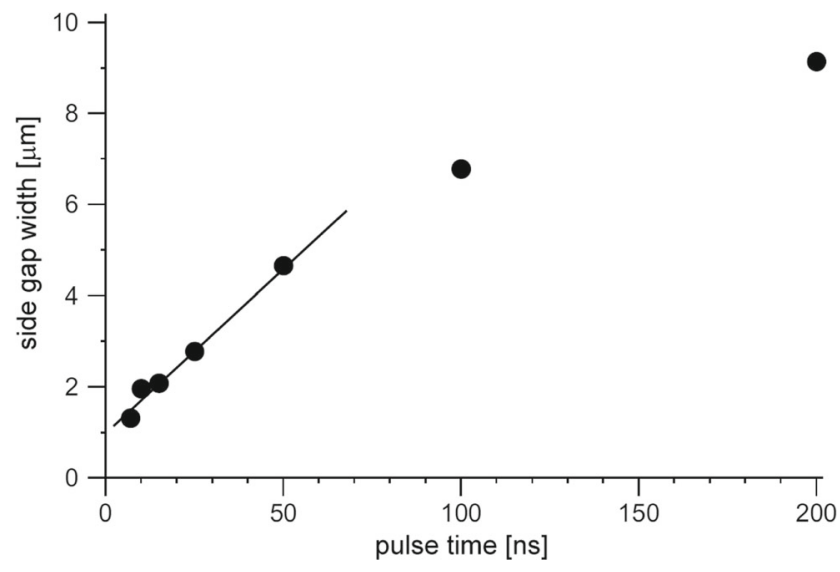

Fig. 6 Relation between side gap width and pulse duration obtained with $50 \mu \mathrm{m}$ diameter cylindrical tool positioned $0.5 \mu \mathrm{m}$ above the 1.4301 stainless steel surface (pulses with $1.6 \mathrm{~V}$ amplitude were applied for $5 \mathrm{~min}$, electrolyte $3 \mathrm{M} \mathrm{HCl} / 6 \mathrm{M} \mathrm{HF}$ ) [6]

charge transport limits are negligible (limiting current density $i_{L}$ is significantly higher than $i_{f}$ ), what is evident in relation $S\left(t_{i}\right)$ (Fig. 6).

According to relation:

$\Delta V_{i}=\eta k_{v} q_{i}$

where $\eta k_{v}$ - electrochemical machinability, volume material removal rate in single voltage pulse $V_{i}$ is proportional to charge $q_{i}$ that was passed through the gap. The value of $q_{i}$ is proportional to interelectrode gap thickness $S$ (Fig. 2d). Based on this relation, dissolution process localization evaluation methodology was presented in $[11,23,24]$. Authors proposed approximation of relation $q_{i}(S)$ as follows:

$q_{i}(S)=\frac{A}{S^{n}}$.

where value of $n$ characterizes dissolution process localization (the higher $n$ means better process localization). Based on the developed process model and computer simulation, the following relations between process parameters and $n$ were found:

- with $t_{i}$ increase the value of $n$ decreases (localization is getting worse),

- decrease of pulse voltage amplitude $U$ increases $n$ (localization improves),

- increase electrolyte conductivity $\kappa$ causes decrease of $n$.

In [38], authors empirically verified conception of application of exponent $n$ as localization factor. Assumed form of approximating function and introduction of dimensionless $n$ factor gives possibility to qualitative comparison of machining localization for different process parameters. However, it is worth to underline that physical interpretation of constant $A$ in Eq. 4 is difficult, because its dimension depends on $n$. 
Fig. 7 SEM images of structures machined on gold foil; electrolyte: $1 \mathrm{M}$ mixture of $\mathrm{LiCl} / \mathrm{DMSO}$, machining parameters: a $U=4.2 \mathrm{~V}$, $t_{i}=20 \mathrm{~ns} ; \mathbf{b} U=5.2 \mathrm{~V}$, $t_{i}=10 \mathrm{~ns} ; \mathbf{c} U=5.6 \mathrm{~V}, t_{i}=20 \mathrm{~ns} ;$ d $U=5.6 \mathrm{~V}, t_{i}=11 \mathrm{~ns}[29]$

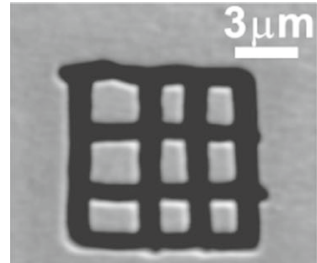

(a)

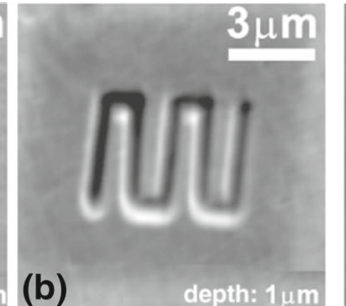

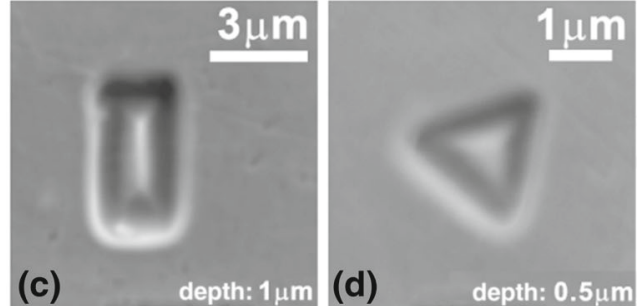

The key impact on ns-PECM resolution has electrolyte conductivity, which determines speed of EDL charge. To start dissolution in distance $S$ from electrode tool, the potential difference in EDL has to be higher than value of activation overpotential for particular anode reaction. The rearrangement of ions in EDL requires a certain response time $t_{i}^{*}<t_{i}$, which depends on current in external circuit and gap (electrolyte) resistance. Decrease of gap thickness $S$ causes resistance decrease (faster rearrangement of ions); however, this decrease also limiting current $i_{L}$ (maximum attainable current density for given reaction). The time
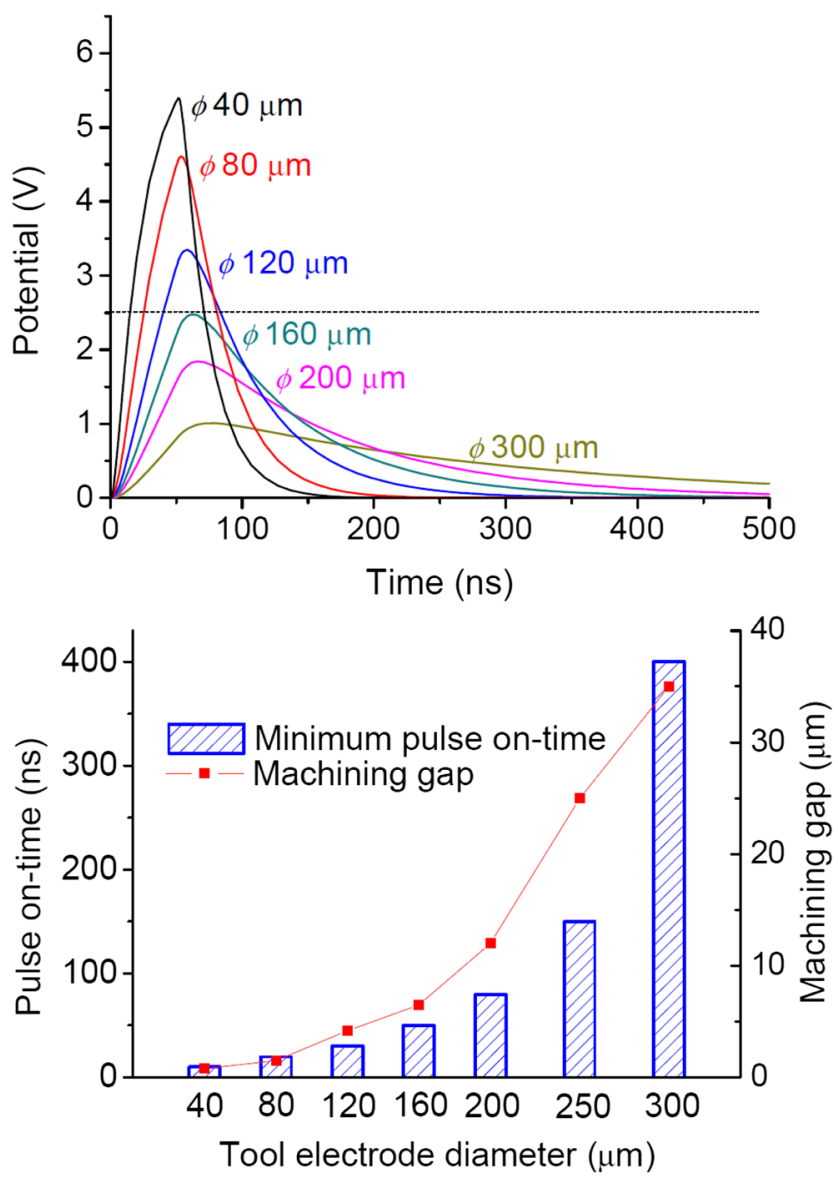

Fig. 8 Left: change of anode potential in time for different diameters of cylindrical electrode tool (pulse time $t_{i}=50 \mathrm{~ns}$ and voltage amplitude $U=6 \mathrm{~V}$ ); right: influence of electrode tool diameter on minimum time of DL charge and thickness of side gap (it can be identified with precision of machining), voltage amplitude $U=6 \mathrm{~V}$ [34] $t_{i}^{*}$ should be as short as possible, what can be achieved by increase of amount of electroactive ions in interelectrode gap (increase of electrolyte concentration). Assuming that polarization of EDL with typical capacity for metalelectrolyte interface $c=10 \mu \mathrm{F} / \mathrm{cm}^{2}$ to potential difference $1 \mathrm{~V}$ needs about 0.1 of ions monolayer, application of electrolyte with concentration $\approx 0.3 \mathrm{M}$ gives possibility to obtain spatial resolution about $10 \mathrm{~nm}$ [40]. For $0.2 \mathrm{M}$ water solution of $\mathrm{HCl}$, it is possible to decrease $t_{i}^{*}$ below $1 \mathrm{~ns}$ and machining of nickel with spatial resolution $\ll 1 \mu \mathrm{m}$ [19]. Possibilities of increase spatial resolution during machining of gold were presented in Fig. 7.

Limits of spatial resolution increase during nanosecond pulse ECM are defined by response time $t_{i}^{*}$ and machining area (electrode dimensions). Response time $t_{i}^{*}$ deviates significantly from theoretical DL time constant $\tau$ (Eq. 1), because it depends also on electrode surface contamination and geometrical structure, electrode dimensions, and way of electrolyte supply [33, 37]. Approximate discussion of $t_{i}^{*}$ relation from electrode area was carried out in [34]. The authors assume that interelectrode gap is charging with constant current and analyzed change of anode potential in time. The result confirm that for faraday current $i_{f}=$ const, increase of machining area causes for $t_{i}=$ const decrease of anode potential and thus decrease of anodic dissolution speed or complete stop of machining (Fig. 8). On the other hand, increase of electrode area causes that anode polarization to the desired potential value needs more time (which effectively means change of the character of the process to the diffusion limited state). Therefore in majority cases, machining in ns-PECM is carried out in kinematics of milling with application of electrode tool with

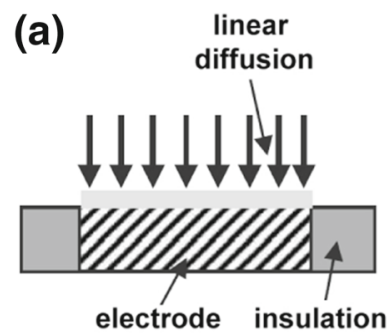

(b)

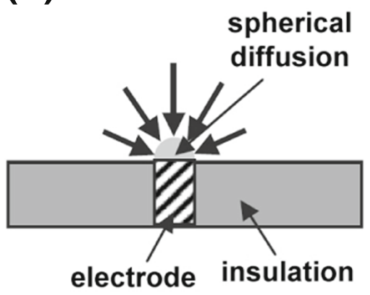

Fig. 9 Scheme showing the difference between linear (a) and spherical (b) diffusion [54] 

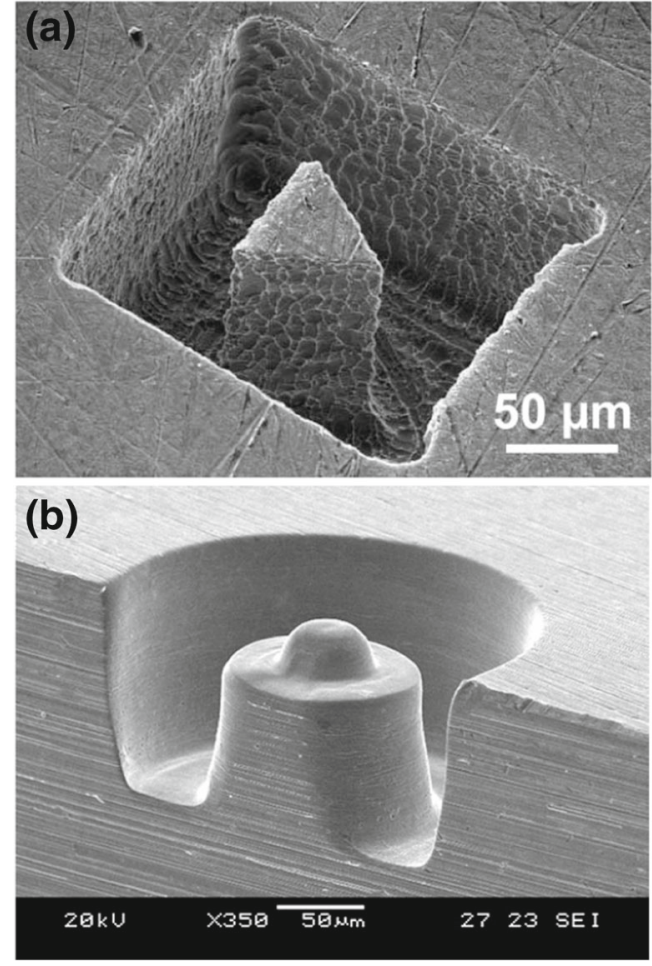

Fig. 10 Examples of ns-PECM milling application: a a prism machined in a stainless steel sheet in two stages: fast rough machining with $143 \mathrm{~ns}$ pulses followed by a slow fine stag with $50 \mathrm{~ns}$ pulse duration (tool: cylindrical $\mathrm{W}$ wire with $30 \mu \mathrm{m}$ diameter, electrolyte $3 \mathrm{M}$ $\mathrm{HCl} / 6 \mathrm{M} \mathrm{HF}$ ) [6]; b micro hemisphere with $60 \mu \mathrm{m}$ diameter machined by rough and finish cut ( $45 \mu \mathrm{m}$ electrode, material: $304 \mathrm{SS}$, workpiece potential $6 \mathrm{~V}, 0 \mathrm{~ns}$ pulse on-time, $1 \mu$ s period) [15]

diameter $<100 \mu \mathrm{m}$. There are also examples of successful application of STM tip as electrode tool [29]. However, decrease of electrode tool dimensions causes EDL capacity decrease and then main impact on $t_{i}^{*}$ has parasitic capacitance $C_{p}$ in external circuit. For example, specific electrical capacitance of platinum electrode immersed in $0.1 \mathrm{M}$ electrolyte is equal $40 \mu \mathrm{F} / \mathrm{cm}^{2}$, what for cylindrical electrode with $1 \mathrm{~mm}$ diameter gives EDL capacity $\approx C=1 \mu \mathrm{F}$. It is significantly higher value than stray capacitance in electrochemical experiments. However, for electrode with diameter
$1 \mu \mathrm{m}$, DL capacity is in range of picofarads, what is comparable to or less than capacitance $C_{p}$ of external power supply circuit [37].

\subsection{Limits of ns-PECM accuracy}

In order to estimate limits of nanosecond ns-PECM accuracy, the case of spherical electrode with radius $r_{0}$ which is immersed in electrolyte with specific conductivity $c^{\infty}$ and connected to external source of potential was considered. When in moment $t=0 \mathrm{~s}$ the external potential increase to value for which oxidation or reduction reaction on the electrode take place, the ions diffusion is described by Fick's second law. For spherical coordinates it gives: $[33,37]$ :

$\frac{\delta c}{\delta t}=D \frac{\delta^{2} c}{\delta r^{2}}+\frac{2 D}{r} \frac{\delta c}{\delta r}$

with following border conditions: for $t=0$ and $r>r_{0}$ : $c=c^{\infty}$; for $t>0$ and $r=\infty: c=c^{\infty}$; for $t>0$ and $r=$ $r_{0}: c=0$; where $r$ distance from electrode center, $r_{0}$ radius of spherical electrode, $D$ diffusion coefficient, $c=c(r, t)$ distribution of electroactive ions concentration.

Solution of above mentioned equations leads to equation which describes change of ions current in time $t$ :

$i(t)=n F A c^{\infty}\left(\frac{D}{r_{0}}+\sqrt{\frac{D}{\pi t}}\right)$

where $n$ the number of electrons taking part in the reaction, $A$ area of the electrode. From Eq. 6 results, that system response to the potential jump consist of two parts: independent and time-dependent. For very short time, according to equation $\delta=\sqrt{\pi D t}$ [4], thickness of diffusion layer $\delta$, is much smaller than radius of the electrode, what causes that diffusion take place according to linear diffusion model. For such conditions, mass transport takes place in normal direction to electrode surface (Fig. 9a) and dominant role has second part of the Eq. 6, which is proportional to $\sqrt{\frac{1}{t}}$. With the course of the reaction importance of time dependant part becomes secondary and mass transport depends primarily on electrode radius $r_{0}$. It is described by first part of the Eq. 6, which characterize spherical diffusion
Fig. 11 Examples of ns-PECM wire cutting application [13]
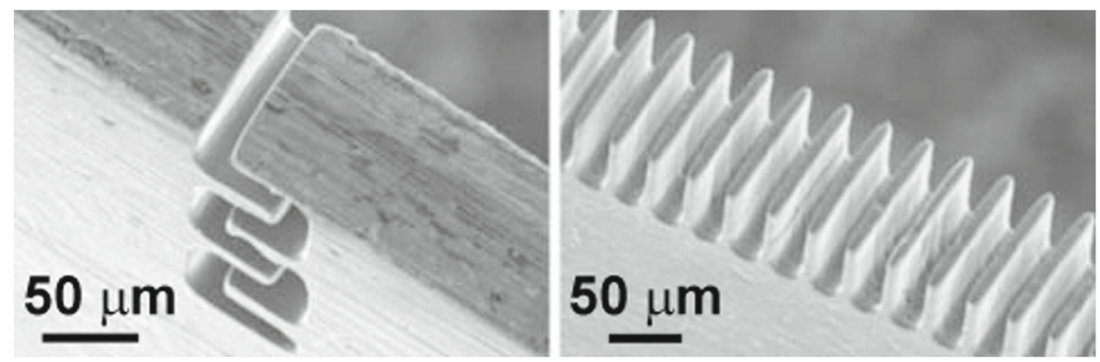


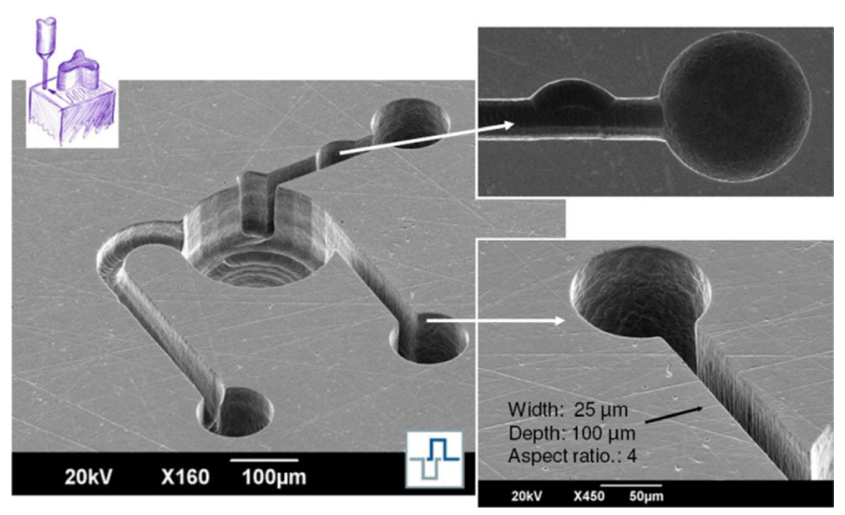

Fig. 12 Example of ns-PECM milling application: a structure for microfluidics (material: 1.4441 steel) (ECMTEC GmbH Holzgerlingen, Germany)

(Fig. 9b), in which speed of electrolysis is balanced by ions flux diffusing toward electrode surface. In aspect of ideal reproduction of electrode tool shape (what means the best accuracy), electrochemical dissolution should be carried out with linear diffusion. Therefore, based on the above presented considerations, the following condition for ns-PECM can be formulated:

$t_{i}^{*} \leq \pi t_{i}<<\frac{r_{0}^{2}}{D}$

which gives relation between pulse time and electrode dimensions. From Eq. 7 theoretical limit of pulse time, which gives possibility to ideal reproduction of electrode tool shape can be estimated. Assuming, for example, $\mathrm{Ag}^{+}$ ion diffusion coefficient in $0.1 \mathrm{M}$ water solution of $\mathrm{KNO}_{3}$ $D=1.55 \cdot 10^{5} \mathrm{~cm}^{2} / \mathrm{s}$ [54] following values are obtained:

- dla $r_{0}=0,1 \mathrm{~mm} \pi t_{i}<<6.45 \cdot 10^{-11} \mathrm{~s}$

- dla $r_{0}=0,01 \mathrm{~mm} \pi t_{i}<<6.45 \cdot 10^{-13} \mathrm{~s}$

Taking into account recent state of art in energy sources for electrochemistry such values of $t_{i}$ are unattainable.

\section{Perspectives an limitations of ns-PECM industrial application}

The workpiece in ns-PECM can be shaped with different typical for ECM kinematics variants as sinking or hole drilling [1, 10, 12, 14, 32, 34, 49], machining with universal electrode tool $[13,15,28,50]$ or in kinematic analogous to wire cutting [41, 46, 51, 53]. Selected examples of application were presented in Figs. 10, 11, 12, and 13. However, it is worth to underline that this result was obtained in laboratories. In spite of numerous publications concerning high potential of ns-PECM process, this technology is not widely used in the industry. Attempt to commercialize of ns-PECM process has been taken by only one company (ECMTEC), which offered machine-tool and technological solutions for ns-PECM industrial application. Unfortunately, this company no longer exist. The author believes that the problems of commercialization are connected with the following reasons:

- physical limits (parasitic inductance) of power supply unit, what affects speed of EDL charging,

- aggressive electrolytes used in the process,

- precise choice of the electrolyte for machined material,

- difficulties in machining of metal alloys (heterogeneity of the structure and composition has significant impact on surface after machining).

It can be stated that the biggest limits of further development of nanosecond pulse ECM are difficulties in upscaling the process. It results from first of the listed above reasons. Increase of electrode tool area while maintaining other conditions of the process (such as pulse time and current density) requires delivery of proportionally more charge in the same pulse time $t_{i}$. From the other side, for used in this process pulse frequency, reactance of the power supply circuit increases significantly and limits speed of charge flow. So, achieving the required level of EDL charge requires the pulse time $t_{i}$ increase what results in machining accuracy decrease or change the character of the process to diffusion
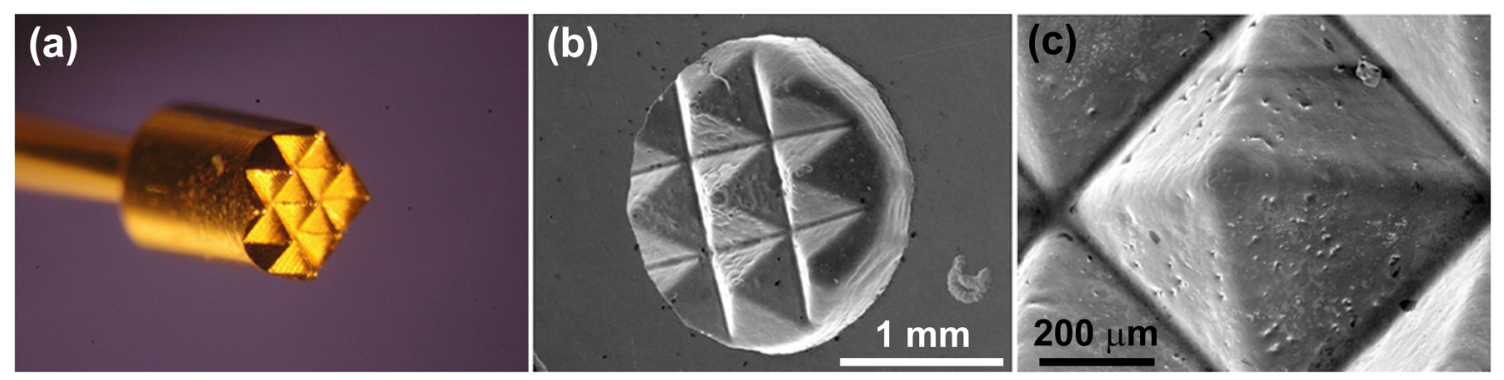

Fig. 13 Example of ns-PECM sinking application: gold electrode tool (left) and 1.4301 steel machined with a modified $\mathrm{HF} / \mathrm{HCl}$ electrolyte (right) [9] 
limited. Therefore, in majority of publications concerning ns-PECM, the results of drilling holes with diameter $\ll 500 \mu \mathrm{m}$ or milling with cylindrical electrode with diameter $<100 \mu \mathrm{m}$ are presented. In case of machining large areas, application of specially designed high current voltage-pulse generators are required [5]. Problems of nanosecond pulse machining scaling-up is not widely discussed in literature; however, in available papers, as a solution proper selection or doping of electrolyte in order to decrease anode potential at which dissolution occurs [9]. It gives even the possibility to sinking with electrode diameter about $1 \mathrm{~mm}$ (Fig. 13); however, electrolyte and electrolyte additives should be carefully balanced. The most popular is application of universal electrode tool with simple shape (working tip is cylindrical, conical, pin or disc) wherein diameter of the electrode is usually less than $100 \mu \mathrm{m}$. The desired shape of the element is achieved by multiple passes of the working tool (similar to milling).

As an area of ns-PECM application single and small series production of tools and prototypes with 3D shapes is suggested. On the other hand, dependence of machining results from heterogeneity of the structure and composition of workpiece material and necessity to precise choice of the electrolyte (composition, conductivity, add additives) significantly decreases flexibility of this method.

\section{Summary}

Based on the data presented in the paper review of ultrashort voltage pulses electrochemical machining, one can state that this process gives possibility to obtain extremely high localization of anodic dissolution. On the other hand, process principles cause, that ns-PECM has number of limitations, which stop its wider application in micromanufacturing industry. The author believes that until the problems hightailed in the paper will not be addressed, transfer of ns-PECM from laboratory scale to industrial process will be difficult. The chances of ns-PECM process further development should be also considered in the context of other micromachining methods state of the art. Recently, significant progress was made in this area, what reduces industrial pull for discussed process further development.

Open Access This article is distributed under the terms of the Creative Commons Attribution 4.0 International License (http:// creativecommons.org/licenses/by/4.0/), which permits unrestricted use, distribution, and reproduction in any medium, provided you give appropriate credit to the original author(s) and the source, provide a link to the Creative Commons license, and indicate if changes were made.

\section{References}

1. Se HA, Ryu SH, Deok KC, Chong NC (2004) Electro chemical microdrilling using ultra short pulses. Precis Eng 28:129134

2. Bhattacharyya B, Munda J (2003) Experimental investigation on the influence of electrochemical machining parameters on machining rate and accuracy in micromachining domain. Int $\mathbf{J}$ Mach Tools Manuf 43:1301-1310

3. Bhattacharyya B, Munda J, Malapati M (2004) Advancement in electrochemical micro-machining. Int $\mathrm{J}$ Mach Tools Manuf 44(15):1577-1589

4. John OMB, Amulya KNR, Gamboa-Aldeco M (2000) Modern Electrochemistry, 2A. Fundamentals of Electrodics. Kluwer Academic Publishers, New York, second edition

5. Burkert St, Schulze H-P, Gmelin Th, Leone M (2009) The pulse electrochemical micromachining (PECMM) - specifications of the pulse units, Int J Mater Form, 645-648

6. Cagnon L, Kirchner V, Kock M, Schuster R, Ertl G, Thomas G, Heinz Kck W (2003) Electrochemical micromachining of stainless steel by ultrashort voltage pulses. Zeitschrift fr Physikalische Chemie 217:299-313

7. Madhav D, Derek H (1997) Electrochemical micromachining: an environmentally friendly, high speed processing technology. Electrochim Acta 42(20-22):3007-3013. Electrochemical Microsystem Technologies

8. Davydov AD, Volgin VM, Lyubimov VV (2004) Electrochemical machining of metals: Fundamentals of electrochemical shaping. Russ J Electrochem 40(12):1230-1265

9. Eva F, Thomas G (2009) The machining of large areas with electrochemical micromilling. In: Proceedings of The International Symposium on ElectroChemical Machining Technology INSECT 2009, volume 1 of Applied Electrochemistry in Material Science, pages 59-64. Fraunhofer Verlag

10. Fan Z-W, Hourng L-W (2011) Electrochemical micro-drilling of deep holes by rotational cathode tools. Int J Adv Manuf Technol 52:555-563

11. Dorota G (2006) Electrochemical microshaping with ultrashort pulses (thesis in Polish). Warsaw University of Technology, PhD thesis

12. Chan HJ, Bo HK, Chong NC (2009) Micro electrochemical machining for complex internal micro features. CIRP Ann Manuf Technol 58(1):181-184

13. Kim BH, Na CW, Lee YS, Choi DK, Chu CN (2005) Micro electrochemical machining of 3D micro structure using dilute sulfuric acid. CIRP Ann Manuf Technol 54(1):191-194

14. Kim BH, Park BJ, Choi SH, Lee YS, Chu CN (2005) Application of multiple electrodes in micro-ecm. In: ASPE Proceedings, Norfolk, VA, October 9-14

15. Kim BH, Ryu SH, Choi DK, Chu CN (2005) Micro electrochemical milling. J Micromech Microeng 15(1):124-129

16. Viola Kirchner (2001) Elektrochemische Mikrostrukturierung mit ultrakurzen Spannungspulsen. PhD thesis, Freien Universitat Berlin

17. Kirchner V, Cagnon L, Schuster R, Ertl G (2001) Electrochemical machining of stainless steel microelements with ultrashort voltage pulses. Appl Phys Lett 79(11):1721-1723

18. Kirchner V, Xia X, Schuster R (2001) Electrochemical nanostructuring with ultrashort voltage pulses. Acc Chem Res 34:371377

19. Kock M, Kirchner V, Schuster R (2003) Electrochemical micromachining with ultrashort voltage pulses a versatile method with lithographical precision. Electrochim Acta 48:3213-3219 
20. Kock M, Klammroth V, Cagnon L, Schuster R (2004) Electrochemical micromachining of steel with ultrashort voltage pulses. In: Proceed. of INSECT 2004, Dusseldorf

21. Kozak J (2004) Thermal models of pulse electrochemical machining. Bulletin of The Polish Academy of Sciences - Technical Sciences, 52

22. Kozak J, Gulbinowicz D, Gulbinowicz Z (2007) Thermal limitations in pulse electrochemical machining (pecm). In: Proceeding of the International Symposium on Electrochemical Machining Technology INSECT 2007, Chemnitz

23. Kozak J, Rajurkar KP, Gulbinowicz D, Gulbinowicz Z (2007) Investigations of micro electrochemical machining using ultrashort pulses. In: Proceeding of the XV International Symposium of Electro machining ISEM07, pages 319-324, Pittsburgh

24. Kozak J, Gulbinowicz D, Gulbinowicz Z (2008a) The mathematical modeling and computer simulation of pulse electrochemical micromachining. Eng Lett 16(4):556-561

25. Kozak J, Gulbinowicz Z, Gulbinowicz D (2009) IAENG Transactions On Engineering Technologies, chapter The Mathematical Modeling and Computer Simulation of Electrochemical Micromachining Using Ultrashort Pulses, pages 174-185. American Institute of Physics

26. Kurita T, Chikamori K, Kubota S, Hattori M (2006) A study of three-dimensional shape machining with an $\mathrm{EC} \mu \mathrm{M}$ system. Int $\mathbf{J}$ Mach Tools Manuf 46:1311-1318

27. Lee ES, Baek SY, Cho CR (2007) A study of the characteristics for electrochemical micromachining with ultrashort voltage pulses. Int J Adv Manuf Technol 31(7-8):762-769

28. Liu Y, Di Z, Zhu L (2012) Micro electrochemical milling of complex structures by using in situ fabricated cylindrical electrode. Int J Adv Manuf Technol 60:977-984

29. Ma X, Schuster R (2011) Locally enhanced cathodoluminescence of electrochemically fabricated gold nanostructures. J Electroanal Chem 662:12-16

30. Masuzawa T (2000) State of the art of micromachining. CIRP Ann Manuf Technol 49(2):473-488

31. Mathew R, Sundaram MM (2012) Modeling and fabrication of micro tools by pulsed electrochemical machining. J Mater Process Technol 212:1567-1572

32. Maurer JJ, Mallett JJ, Hudson JL, Fick SE, Moffat TP, Shaw GA (2010) Electrochemical micromachining of hastelloy b-2 with ultrashort voltage pulses. Electrochim Acta 55(3):952-958

33. Montenegro MI, Queirs MA, Daschbach JL (eds.) Microelectrodes: Theory and Applications, volume 197 of NATO ASI Series, Series E: Applied Sciences. Kluwer Academic Publishers, 190

34. Park BJ, Kim BH, Chu CN (2006) The effects of tool electrode size on characteristics of micro electrochemical machining. CIRP Ann Manuf Technol 55(1):197-200

35. Rajurkar KP, Kozak J, Wei B, McGeough JA (1993) Study of pulse electrochemical machining characteristics. CIRP Ann Manuf Technol 42(1):231-234

36. Rajurkar KP, Wei B, Kozak J, McGeough JA (1995) Modelling and monitoring interelectrode gap in pulse electrochemical machining. CIRP Ann Manuf Technol 44(1):177-180
37. Scharifker BR (1992) Microelectrode techniques in electrochemistry. Mod Aspects Electrochemistry 22:467-520

38. Schulze H-P, Ruszaj A, Gmelin T, Kozak J, Karbowski K, Borkenhagen D, Leone M, Skoczypiec S (2010) Study of the process accuracy of the electrochemical micro machining using ultra nanosecond and short microsecond pulses. In: Proceedings of the 16th International Symposium on Electromachining, pages 651-656, April 19-23

39. Schuster R, Kirchner V, Xia XH, Bittner AM, Ertl G (1998) Nanoscale electrochemistry. Phys Rev Lett 80:5599-5602

40. Schuster R, Kirchner V, Allongue P, Ertl G (2000) Electrochemical micromachining. Science 289(5476):98-101

41. Shin HS, Kim BH, Chu CN (2008) Analysis of the side gap resulting from micro electrochemical machining with a tungsten wire and ultrashort voltage pulses. J Micromech Microeng $18: 1-6$

42. Skoczypiec S, Ruszaj A (2014) A sequential electrochemicalelectrodischarge process for micropart manufacturing. Precis Eng 38:680-690

43. Skoczypiec S, Ruszaj A, Piotr L (2010) Research on electrochemical dissolution localization in case of micro machining with ultra short pulses. In: Proceedings of the 16th International Symposium on Electromachining, pages 319-322, April 19-23

44. Norio T (1983) Current status in, and future trends of, ultraprecision machining and ultrafine materials processing. CIRP Ann Manuf Technol 32(2):573-582

45. Wang MH, Zhu D (2009) Fabrication of multiple electrodes and their application for micro-holes array in ecm. Int J Adv Manuf Technol 41:42-47

46. Wang S, Di Z, Zeng Y, Liu Y (2011) Micro wire electrode electrochemical cutting with low frequency and small amplitude tool vibration. Int J Adv Manuf Technol 53(5-8):535-544

47. Wang W, Di Z, Ningsong Q, Huang S, Fang X (2010) Electrochemical drilling inclined holes using wedged electrodes. Int J Adv Manuf Technol 47(9-12):1129-1136

48. Wijers J (2014) Upgrading to pem. Mikroniek Professional J Precis Eng 54(3):48-53

49. Ye Y, Natsu W, Zhao W (2011) Realization of eco-friendly electrochemical micromachining using mineral water as an electrolyte. Precis Eng 2011:204-213

50. Yong L, Di Z, Yongbin Z, Shaofu H, Hongbing Y (2010) Experimental investigation on complex structures machining by electrochemical micromachining technology. Chin J Aeronaut 23:578584

51. Zeng Y-B, Qia Y, Wang S-H, Di Z (2012) Enhancement of mass transport in micro wire electrochemical machining. CIRP Ann Manuf Technol 61(1):195-198

52. Zhang Z, Di Z (2008) Experimental research on the localized electrochemical micro-machining. Russ J Electrochem 44(8):926930

53. Zhu D, Wang K, Qu NS (2007) Micro wire electrochemical cutting by using in situ fabricated wire electrode. CIRP Ann Manuf Technol 56(1):241-244

54. (2007). In: Zoski CG (ed) Handbook of Electrochemistry. Elsevier B.V. 